\title{
Analysis on the Improvement of Job Satisfaction of Employees in Small and Medium-Sized Science and Technology Enterprises
}

\author{
Mou-sheng Liu \\ Luoyang Normal University \\ Luoyang, China \\ Email: jooob@163.com
}

\begin{abstract}
Innovation is the first driving force for the development of small and medium-sized science and technology enterprises. How to improve the satisfaction of the employees in small and medium-sized science and technology enterprises in order to stimulate innovation becomes more and more important. However, at present, there are various problems in the promotion of job satisfaction in small and medium-sized science and technology enterprises. Small and medium-sized science and technology enterprises need to improve the employees' job satisfaction by setting up a flexible organic organization structure, giving the employees challenging jobs, strengthening the training and selection of scientific and technological employees, and establishing a multi-directional career development track to increase their job satisfaction. And then promote small and medium-sized technology-based enterprise staff innovation and performance.
\end{abstract}

Keywords-job satisfaction; small and medium-sized science and technology enterprises; flexible work system.

\section{INTRODUCTION}

Small and medium-sized science and technology enterprises are some kind of enterprises with obvious knowledge-intensive characteristics. The staff is mainly knowledge workers. For small and medium-sized technology enterprises, the innovation of employees' mental work is the key to their success, and for the mental workers, their job satisfaction is the key point to their work enthusiasm and innovation. More and more small and medium-sized science and technology enterprises pay more and more attention to how to improve employee job satisfaction. However, lots of small and medium-sized science and technology enterprises are facing many issues about improving job satisfaction of employees, this essay will outline the possible solution to these issues.

\section{The Definition OF Job SATISFACtiOn AND THE MEANING OF IMPROVING JOB SATISFACTION.}

Generally speaking, job satisfaction refers to the employees' feeling that the work itself can meet or contribute to the needs of their own work values[1]. And the pleasure arises because of these. The improvement of job satisfaction can attract the excellent talents to join and reduce the turnover rate, and maintain the stability and growth of the enterprise's talent team, so as to increase the dependence of employees on the psychological and cohesion of the company. Companies improve their performance by improving job satisfaction. Compared with the staff of ordinary enterprises, small and medium-sized high-tech employees have huge capital value, creativity, hard to replace, difficult to supervise, so the improvement of job satisfaction is particularly important. Improving the satisfaction degree of scientific and technological employees can keep the employees and enhance the innovation ability of the scientific and technological employees, and finally enhance the competitive advantage of the enterprises.

\section{A. Attracting and retaining talents}

In small and medium-sized science and technology enterprises, the ratio of highly qualified technical talents is very large. They are usually graduates of famous universities. They have sufficient knowledge of capital. The average age of employees of small and medium-sized technological enterprises is no more than 30 years old, especially in electronics. In telecommunications and other industries, the age structure advantage of talents is even more obvious. According to Maslow's theory of the hierarchy of needs, the survival needs are not the needs they first consider in view of the characteristics of such talents. What they value more is seeking self-development, increasing autonomy and realizing personal value. In addition, conflicts between the supply and demand of skilled personnel are easy to produce high mobility. If small and medium-sized science and technology enterprises want to retain and attract outstanding talents, they should enhance their satisfaction and sense of belonging, so that they can be at home in the company. Willing to serve the company, thereby reducing the wastage rate.

\section{B. Increasing the value of assets by enhancing the innovative ability of scientific and technological personnel \\ In an industrial enterprise, one hard-working employee can be $30 \%$ to 40 more efficient than the average employee, but in a tech company, a creative employee can be $500 \%$ or more efficient than the average employee, mainly because in the information technology society, the output of labor is more intellectual and creative labor[2]. For the high-tech employees, to improve their satisfaction, to encourage employees to work}


with greater enthusiasm, so as to stimulate employees' awareness of innovation, improve their innovative ability, create higher work efficiency, High efficiency means greater efficiency. Science and technology is the first productive force, and the improvement of innovation ability will greatly increase the production and the value of the enterprise's assets.

\section{THE CHARACTERISTICS OF JOB SATISFACTION IN SMALL AND MEDIUM-SIZED SCIENCE AND TECHNOLOGY ENTERPRISES}

Because of the characteristics of the small and medium-sized science and technology enterprises, the employees are different from other non-technology enterprises in the whole, and the influencing factors of job satisfaction are far more than salary and bonus.

\section{A. In pursuit of self-satisfaction, the level of demand is high.}

As the level of economic development in our country is not high, the wages and bonuses of ordinary employees in most enterprises are not high. This also makes the dominant demand for the majority of employees in non-technology enterprises to be economic demand, while the employees of technology-based enterprises generally have higher wages and more bonuses. Basically, economic needs are met[3]. In addition, these employees are generally highly educated, have a strong personal desire to develop, and pursue self-fulfilling needs, so compared with the employees of other enterprises, The level of demand pursued by the employees of small and medium-sized science and technology enterprises is generally higher than that of economic needs, security needs and social needs, and the satisfaction of higher levels of respect and self-realization needs is more pursued.

\section{B. Seeking the recognition of the work groups and corporate values.}

The identity of values is an aspect of high-level individual needs. For the employees of science and technology enterprises, the lower level needs, such as their physiological needs, have generally been satisfied. Employees will pursue higher levels of needs, such as they want to work with like-minded colleagues, they want to work in a company that shares their own values if they feel that their colleagues' values are in line with their own. They'll get higher satisfaction.

\section{Prefer flexible working methods.}

The labor of employees in technology-based enterprises belongs to mental work and is creative. This creative process is invisible and unrestricted. There are no definite steps and processes, and the work process is not easy to assess. In addition, the nature and characteristics of their work determine that the employees of technology-based enterprises are more suitable for flexible working methods. for this reason, Most science and technology enterprises rarely ask the employees to clock in or out, or even specify the manner in which employees should complete their work tasks. This flexible way of work is an important factor to affect the job satisfaction of science and technology enterprises.

\section{THE STRATEGIES TO IMPROVE THE SATISFACTION OF SMALL AND MEDIUM-SIZED SCIENTIFIC AND TECHNOLOGICAL EMPLOYEES}

The staff of the science and technology enterprise have higher autonomy, individuality and the innovative spirit, not only pay attention to the economic factors, but also value the realization of the personal value and the satisfaction of the work process. In order to improve the satisfaction of the science and technology staff, the enterprise can take into account the following aspects.

\section{A. Establishing the flexible structure of organic structures.}

The organizational structure used by large-scale enterprises and production enterprises generally tends to be bureaucratic, and the bureaucratic organization structure is obviously not suitable for small and medium-sized scientific and technological enterprises because of its many rules and regulations, strict hierarchy and complex procedures[4]. The small and medium-sized scientific and technological enterprises should establish a more flexible and flexible organizational structure, which can give more autonomy to the employees due to their relatively loose and flexible structure and can improve the satisfaction of the staff of the small and medium-sized scientific and technological enterprises. Small and medium-sized scientific and technological enterprises establish a flexible, model-based organization structure, which mainly requires the following conditions:

- Flexible working system. Because the employees of small and medium-sized science and technology enterprises generally prefer flexible working methods, The development of the flexible working system can satisfy the demand preference of the staff. The general enterprise has a strict duty-to-work card system, and the small and medium-sized scientific and technological enterprises can abolish the system, allow the employees to freely arrange the time of work within a certain time, and can even allow the staff to choose work flexibly.

- More autonomy for employees. Compared with simple manual workers, the staff of the science and technology enterprise is not willing to be ordered, they do not like the plan and the way that the boss order them what to do and how to do, so the enterprise should give the employees more autonomy, and let them have the opportunity to understand the cooperative relationship between the various departments within the company, to ignite their enthusiasm for work and to effectively play the innovation ability of the staff of the scientific and technological enterprises[5].

- The equal relationship between superior and subordinate. The staff of the science and technology enterprise have a strong self-satisfaction and wish to be respected by others. The manager of the general enterprise likes to be superior, which is to be unliked by the employees of the scientific and technological enterprises. When design the structure of small and medium-sized scientific and technological enterprises, on the one hand, it is necessary to reduce the management level, set a flat type 
organization structure, reduce the grade, and on the other hand, the superior should also put on the position to get along with the lower level in a friendly and frank manner, and care for the lower level. To understand the living conditions, thoughts and emotions in the lower level, and the difficulties in the work. The managers of the scientific and technological enterprises should treat the staff as the colleagues and the family members, create a harmonious family-style relationship between the upper and the lower-level, and improve the employee's satisfaction, thus increasing the employee's loyalty to the enterprise.

- Flexible employee responsibilities and working procedures. For tech-based employees, they don't like to be regulated, and the tight working procedures may lose all of the passion and creativity of the staff of the tech enterprise, thus reducing job satisfaction. In view of the professional and high requirements of the knowledge and technology of the staff of the science and technology enterprises, they are much more aware of their work than their owners, and the company wants to give the best play to the scientific and technological innovation ability of the staff, It is necessary to have the courage to give full power to the science and technology staff, and to take the heavy task to believe that they have the ability to analyze and solve the problem independently[6].

\section{B. Provide as many opportunities as possible to provide training and promotion.}

The staff of small and medium-sized science and technology enterprises often have higher levels of demand, and pay more attention to the realization of self-worth. The scientific and technical staff advocate science and technology, and can carry out the training of the science and technology of the staff according to the scientific and technical direction of the science and technology staff, and regularly invite the authoritative experts to train the staff, and also can carry out relevant education and training to the staff according to the latest technology and technology, Improve the staff's scientific literacy, further improve the self-value of the staff, and finally achieve the effect of improving the employee's satisfaction. After a series of training of the staff, the enterprise needs to promote and select the staff according to the learning situation and the working ability of the staff, and the reasonable and effective selection indicates that the employee's work is realized by the requirements of the enterprise approval and the affirmation, the promotion demand and the self-value realization, The satisfaction of the staff will be greatly improved.

\section{Providing challenging work For the staff of the science and technology enterprise.}

The challenging work can provide a kind of inspection standard for the strength of the individual's ability. Science and technology staff generally have the motivation to be willing to participate in the challenge, the pursuit of excellence, and the achievement of the goal, and the achievement of this motivation is the direct expression of the sense of achievement. Science and technology staff generally have a high degree of achievement, and always strive to make things better, they want to take responsibility for work, and they like moderate risks. Therefore, small and medium-sized scientific and technological enterprises should provide the staff with challenging work and make the individual's personal capacity fully play. In order to improve the enthusiasm of the staff of the scientific and technological enterprises, to stimulate them to play a more potential in their work, to improve their satisfaction and to create more value for the enterprises. In the day-to-day human resource management, small and medium-sized scientific and technological enterprises should analyze the post requirements and the requirements of the staff as much as possible so as to make the work difficulty and challenge, so as to improve the satisfaction of the staff.

\section{Setting up a multi-direction career development track for employees.}

Traditional employee career development track is unidirectional, and employees only have vertical upward position advancement. And most of the employees in technology-based enterprises are professional groups based on technology and market. This kind of consequence is that the technicians often enter the management field that they are not good at, and lead to inefficient management. At the same time, it can cause employees' values not to be reflected, thus dissatisfaction with the work, and eventually lead to the loss. To achieve a two-track career development system can improve the satisfaction of technology-based employees, especially those who are science-oriented. Professionals are free to choose to develop on the technical track or on the management track, and the two tracks have the same level. Because the technological innovation of science and technology enterprises is very important, enterprises have a great demand for technical knowledge personnel such as engineers and scientists; And technicians want to develop their expertise, which can deepen their qualifications in a certain field, thereby enhancing their own market value. Therefore, the enterprise can provide a variety of development channels for technical personnel, which can improve the job satisfaction of those professionals with rich expertise and skills, and then retain the excellent staff.

\section{E. Improving employee health benefits can improve job satisfaction by improving employee health benefits.}

The small and medium-sized technology companies can carry out a variety of employee health management activities. On one hand, it can enrich the daily life of employees, enhance their understanding of their own health, develop good living habits, and thus improve the physique of employees. On the other hand, it can improve the social image of small and medium-sized technology enterprises, attract excellent talents, at the same time, it can improve the cohesion among the employees, shorten the distance of employees, and enhance the social responsibility of small and medium-sized technology companies. Many small and medium-sized technology companies are sparing no effort to improve employee health benefits, such as Google and Smartisan. Specific measures can be taken to improve employee health and welfare in the following areas: 


\section{CONCLUSION}

- The opening of the gymnasium. Due to long-term sitting for scientific research, the employees of tech-based enterprises have a series of health problems. Health is the capital of the revolution. Therefore, enterprises can open gyms for employees in the office area, so that employees can exercise at any time when they are tired so that their bodies and minds can be effectively relaxed and their satisfaction can be improved. And make the staff have a healthy physique and sufficient energy to work.

- Hiring professional fitness coaches. At Microsoft, each company has its own fitness equipment room, with a personal trainer, employees in free time can exercise the body relax. In view of the fact that some employees are not very professional in fitness, enterprises should employ professional fitness coaches, regularly carry out fitness education and training for their employees, so as to increase their understanding of fitness knowledge, so as to prevent adverse reactions caused by their own fitness. Affect the employee's passion for physical exercise.

- Opening of staff canteen. The employees of science and technology enterprises belong to the group of high scientific and cultural literacy, they pay more attention to a healthy and healthy diet. Enterprises open a clean and healthy staff canteen to provide survival and development of food balance, which can greatly improve the satisfaction of employees.
It is a long-term and arduous task to release the staff's passion, enhance the staff's ability of scientific and technological innovation, make the scientific and technological concept into a product for practical production, and increase the employee's satisfaction. There may be a variety of problems in the implementation process that require an implementable plan from the management of the enterprise. In the process of implementation, we should consider the feelings of the employees more, start from all aspects, overview the overall situation, deeply analyze the potential and realistic factors that affect job satisfaction, take various measures to enhance job satisfaction and enhance the cohesion of the staff. To create greater wealth for the company.

\section{REFERENCES}

[1] Chen Hui, Study on the Optimization of employee satisfaction and Job quality in Enterprises, J. Journal of Jilin Radio and TV University.11(2014), pp.68-69.

[2] Li Zhen, Study on Job satisfaction Evaluation of Knowledge-based employees in Enterprises, J. Scientific and Economic Society, 2(2012), pp.85-88.

[3] Liu Hongsheng, On how to improve employee's Job satisfaction in small and Medium-sized Private Enterprises, J. Management and Technology of small and Medium-sized Enterprises, 12(2008), pp. 67-68.

[4] Yang Hongyan, How to manage knowledge workers in information society, J. Human Resources Management, 4(2009), pp.107-108.

[5] Wang Xuwen, “Analysis of employee health management in enterprises”, Safety and Health, vol.23, pp. 50-51, Dec 2007. (In Chinese)

[6] Zhong Yafang, "Research and Enlightenment of employee Health Management in American Enterprises”, vol.12, pp. 55-58, Dec 2009. (In Chinese) 